\title{
The High Costs of Being Poor in the Land of the Dream
}

\section{Society and Politics}

\author{
Carol Graham ${ }^{1}$
}

Published online: 18 October 2017

(C) Springer Science+Business Media, LLC 2017

\section{The Failing American Dream}

My contribution to this discussion focuses on the unequally shared American dream. It is based on my new book: Happiness for All? Unequal Hopes and Lives in Pursuit of the American Dream (Princeton Press, 2017). I use traditional measures of income inequality as a point of departure and then use well-being data to highlight inequality in beliefs, hope, and aspirations. The high costs of being poor in the U.S. are more evident in stress, insecurity, and hopelessness than in material deprivation. This hopelessness is, by definition, the opposite of life fulfillment (eudaimonia) and begs the question where lack of hope and opportunity in a rich world fits into Maslow's hierarchy. I cannot answer that question, but I hope that some of my observations contribute to the discussion of the question.

\section{Basic Findings}

There are many ways to measure and document poverty and inequality. While I start with standard economists' measures such as poverty headcounts and Gini coefficients, my main focus is on metrics of well-being. These include evaluative (and implicitly eudaimonic) measures such as life satisfaction and optimism about life in the future, and experienced or hedonic measures such as smiling, stress, and anger the day before.

Carol Graham

cgraham@brookings.edu

1 The Brookings Institution, 1775 Massachusetts Ave., NW, Washington, DC 20036, USA
As Eldar Shafir and Sendhil Mullanaithan have shown so well in their book Scarcity, individuals who experience stress on a daily basis often lose the capacity to plan ahead, as they are so consumed with daily struggles and simply focus on getting through day by day. ${ }^{1}$ As such, they are unable to experience entire dimensions of human well-being, such as eudaimonia. Some very poor score relatively high on experience measures, such as smiling yesterday, either because have naturally cheerful characters and/or they have adapted to their lot and, in Sen's words, "have no choice but to take joy in simple pleasures." Yet the same respondents typically score much lower on questions about how satisfied they are with their lives as a whole, or whether they have purpose or meaning in their lives. This reflects that, for the most part, their inability to choose the kinds of lives they want to lead. They are also typically much less optimistic about their futures, as they lack the capacity to plan for or conceive of those futures.

I find that the poor in the U.S. are significantly less likely to believe that hard work will get them ahead than are the poor in Latin America (in contrast, the rich in the U.S. are more likely to answer this question positively than are the rich in Latin America). The poor in the U.S. are also much more likely to experience stress the previous day than are the poor in Latin America, and much less likely to have smiled the previous day. The gaps between the scores of the rich and poor on all of these markers are also much greater than the gaps between the rich and the poor in Latin America.

The markers of hopelessness are evident in income, education, and employment data; in differences in mortality, marriage, and incarceration rates; and in other signs of societal fragmentation, all of which are starkly different across the poor and the rich in the U.S. Yet trends in hope and well-

\footnotetext{
${ }^{1}$ Mullanaithan, S. and Shafir, E. (2013). Scarcity: The New Science of Having Less and How It Defines Our Lives. New York: Henry Holt.
} 
being are not uniform across all poor cohorts. I find, for example, remarkable levels of optimism among poor blacks (and poor Hispanics, but not as high), in contrast to deep desperation among poor whites.

Our metrics of desperation, stress, and anger match closely with the rising levels of premature mortality across cohorts (concentrated among uneducated whites, as in the mortality data) and places. Desperation, hopelessness, stress, and anger are all higher in rural areas and small towns in the heartland, and lower in the larger coastal cities, mirroring the mortality rate patterns. We also find that places that are more racially diverse (assessed as percent of black and Hispanic respondents) are, on average more satisfied with life and more optimistic about the future, as well as less stressed and angry. Racial diversity also links to a higher percentage of respondents who exercise and a lower percentage of those who smoke. Again, these traits also correspond with urban areas on the coast with lower rates of premature mortality.

Other trends in the data suggest inter-related explanations for what is going on. One is the significant increase in reliance on disability insurance in the past two decades, rising from just under $3 \%$ of the working age population to almost $5 \%$ for men, and from roughly $1.3 \%$ to $4.5 \%$ for women. ${ }^{2}$ While it is particularly concentrated in former coal mining regions, it extends beyond them and mirrors reported pain and high concentrations of prime age men out of the labor force. While disability insurance provides an important and often lifelong safety net for many workers and their families, it also introduces additional barriers to labor force participation. Potential recipients cannot participate in the labor force during the wait time for approval for disability, a period that can last up to two years. Long-term unemployment is one of the conditions that is most strongly associated with unhappiness, and to which most individuals do not adapt.

Other issues related to reliance on disability may also play a role in ill-being, such as via the loss of identity that workers can no longer can participate in the jobs - and daily interactions - they have held over much of their life course. Our data show patterns across the places (states here) with the highest rates (and increases in rates) of reliance on disability insurance and average levels of stress, anger, and worry. Reliance on disability insurance and reported pain, meanwhile, tend to be gateways into the increasing levels of addiction to opioids and other drugs. The secular trend of prime age (25-54 year old) males dropping out of the labor force complements the increase in reliance on disability insurance. Nicholas Eberstadt (2016) projects that $25 \%$ of that cohort will no longer be in the labor force by mid-century (compared with $15 \%$ today). ${ }^{3}$

\footnotetext{
${ }^{2}$ Details on SSDI are from Social Security Advisory Board data, available at: http://www.ssab.gov/Disability-Chart-Book.

${ }^{3}$ Eberstadt, E. (2016). Men without Work: America's Invisible Crisis (West Conshohoken, Pa.: Templeton Press, 2016).
}

A potentially reinforcing factor in this cycle is that these same cohorts, who are disproportionately in remote rural areas, are less likely to have social connections outside their locales. In general, social inter-actions are likely to be more common in densely populated diverse urban places. A recent study from Tufts University finds that the majority of rural youth live in "Civic Deserts", which are defined as places characterized by a dearth of opportunities for civic and political learning and engagement, and without institutions that provide opportunities like youth programming, culture and arts organizations, and religious congregations. ${ }^{4}$ These same areas are also far less likely to have access to broadband internet than are urban ones, which not only limits social connections but also information about jobs outside their immediate environs.

Even the words that different cohorts use highlight this desperation. Those of the wealthy reflect knowledge acquisition and healthy behaviors; those of the poor reflect desperation, short-term outlooks, and patchwork solutions. A study based on a Google word search by David Leonhardt and colleagues finds that the most common words in difficult places to live in America are: guns, videogames, hell, diabetes, fad diets, and stress. In contrast, the most common words in easy places to live are: Ipads, Baby Bjorns, foam rollers, cameras, and exotic travel destinations like Machu Picchu. Different lives and different worlds in America. ${ }^{5}$

\section{What Next? Implications for Maslow?}

What explains lack of hope among the U.S. poor? Inadequate access to health insurance and stable employment play a role, but so do the increasing gaps between the lives of the rich and the poor. These inequities may lead to more unequal outcomes in the future; individuals who do not believe in their futures are unlikely to invest in them. Yet there are also major differences across poor cohorts, as noted above. Why are blacks and Hispanics so much more optimistic? Why are they more resilient to negative shocks and less likely to report depression or commit suicide, as some psychologists find? Expectations and past experience matter. Minorities are making gradual and hard-won progress on many fronts, such as education and life expectancy. Poor and blue-collar whites have experience downward mobility, at least relative to their parents.

This is a complex problem, and there are no magic bullets. My research highlights the important role of well-being metrics in identifying and monitoring trends in hope, desperation, and misery as a first step to understanding the problem

\footnotetext{
${ }^{4}$ Kawashima-Ginsberg, K. and Sullivan, F. (2017). "Sixty Percent of Rural Millennials Lack Access to a Political Life, The Conversation, March 26.

${ }^{5}$ Leonhardt, D. (2015). "In One America, Cameras. In the Other, Guns and Diets." New York Times, August 19, A3.
} 
and its patterns across people and places. My new research as well as that of others like Hall and Shafir, and Haushofer and Fehr - is exploring policies - including experimental ones - in which hope is an important channel in improving outcomes. ${ }^{6}$ Yet there is a long way to go in our understanding. Introducing hope, for example, is likely easier among the very poor in poor contexts (where my experiments in Peru are) than among downwardly mobile cohorts in a very wealthy context like the U.S.

Another unanswered question, which is the subject of this sympoisum, is the implications for Maslow's hierarchy. Where does hopelessness among those who are not materially deprived but rather lack hope, identity, and opportunity in prosperous societies fit into the hierarchy of needs? How do we weigh the needs of these cohorts against those of minorities who remain more deprived in material terms, but who are much more optimistic? How do we weigh rising mortality rates among the former cohorts versus decreasing rates among the latter? I hope that these questions stimulate some discussion (and perhaps some insights into possible solutions).

Carol Graham is Leo Pasvolsky Senior Fellow at the Brookings Institution and College Park Professor at the University of Maryland. She is the author of numerous articles and books, the latest of which is Happiness for All? Unequal Hopes and Lives in Pursuit of the American Dream (Princeton University Press, 2017).

${ }^{6}$ Hall, C. Hall, C., Zhao, J., and Shafir, E. 2014. "Self-Affirmation among the Poor: Cognitive and Behavioral Implications." Psychological Science 25 (2): 619-625; Haushofer, J., and Fehr, E. 2014. "On the Psychology of Poverty." Science 344 (6186); 862-867. 